\title{
O ESTUDO DO DIREITO NO BRASIL E NO PARANÁ
}

\author{
Oscar Martins Gomes \\ Catedrático de Direito Internacional Privado da \\ Faculdade de Direito da Universidade do Paraná.
}

1 - O transcurso agora de um século de autonomia política e administrativa da mais nova Província do Império, a qual, na República, passou a constituir um dos Estados da federação brasileira, sugere, como soe acontecer em celebrações semelhantes, um balanço através do qual a coletividade demonstre sua existência ativa e exprima seu ancêio de progresso.

Nos domínios da cultura, ou seja das manifestações de vida resultantes de desenvolvimento intelectual, entre os vários setores visados, um deles, o relativo ao ${ }^{\circ}$ Direito, merece especial apreciação ante o notório predomínio da influência exercida pelos seus cultores na evolução do país.

Ao conquistar sua independência, libertando-se do jugo de Portugal, contava o Brasil, em 1822, cêrca de quatro milhões e meio de habitantes, concentrados quasi todos nas cidades e vilas do litoral ou próximas a este. População visivelmente escassa para o vastíssimo território, tanto que, aumentada hoje para doze vezes aquele número, dando ao Brasil o lisongeiro título de país latino mais povoado do mundo, oferece ainda a perspectiva de crescimento contínuo para muitas vezes mais do que isso, no decurso do tempo. 
$\mathrm{Na}$ era colonial preponderava o ensino jesuítico, através de colégios e seminários, formando clérigos, bachareis e doutores, cuja erudição se lastreava de conhecimentos das humanidades latinas, gramática, filosofia, retórica, teologia, na expansão provinda do surto da Renascença. Constituiam os letrados de então uma elite intelectual em condições de prover os cargos públicos de maior relêvo e responsabilidade. Os frades franciscanos trouxeram sua sensivel cooperação, a partir de fins do século XVIII, no Rio de Janeiro. Gilberto Freire atribui a tal ordem de estudos (filosofia dos oradores e dos padres, muita palavra, o tom dos apologetas) a "tendência para a oratória que ficou no brasileiro, perturbando-o tanto no esfôrço de pensar como no de analisar as coisas. Mesmo ocupando-se de assuntos que peçam maior sobriedade verbal, a precisão de preferência a efeito literário, o tom de conversa em vez do de discurso, a maior pureza possivel de objetividade, o brasileiro insensivelmente levanta a voz e arredonda a frase. Efeito de muito latim de frade; de muita retórica de padre".

Mas, é de assinalar, também, que, com o Seminário de Olinda, fundado no ano de 1800 pelo bispo Azeredo Coutinho, opera-se a renovação do ensino, com a introdução, no currículo escolar, do ensino das ciências físicas e matemáticas, da botânica, da mineralogia, da química.

A aristocracia rural formada pelos senhores da terra, detentores da fortuna, recebia nova aureola: a da riqueza espiritual. As famílias poderosas mandavam seus filhos estudarem nas universidades da velha Europa: Coimbra, Paris, Montpellier, Cambridge, Oxford. Volviam os diplomados ao Brasil imbuidos das idéias da época, notadamente as dos enciclopedistas do século XVIII, dos postulados da revolução francesa e da declaração de direito da constituição americana. Preparavam-se as gerações de idealistas para a germinação da idéia, afinal vencedora, da nossa independência.

Tudo porém difícil ainda na época de então, de atrazo de meios de comunicação e de transporte, de isolamento das cida- 
des brasileiras, de dispersão da população. Relativamente poucos eram os estudantes brasileiros que cursavam as escolas do velho mundo.

Foi sòmente a partir de 1808, quando se deslocou para o Rio de Janeiro a Côrte de Lisbôa, com D. João VI, que se verificou a creação de cursos profissionais de marinha, exército, medicina, agricultura, economia política, operando-se então como que uma reação contra o sistema de ensino ministrado em geral nos estabelecimentos religiosos, que visavam mais a formação teórica do letrado, do orador, do acadêmico.

Essa conquista de independência na esfera cultural pararia aí ou retrocederia, com o retôrno de D. João VI e sua Côrte para Portugal, em 1821, si não sobreviesse, no ano seguinte, a independência do Brasil, prestigiada e proclamada pelo próprio filho daquele monarca.

2. - O nascente Império, de estrutura unitária, constituido das províncias, em que se haviam transformado as antigas capitanias, e das novas, creadas posteriormente, a do Amazonas, em 1850, e a do Paraná em 1853, passou a ser governado pela Constituição de 1824, outorgada por D. Pedro I, cabendo à União, privativamente, legislar sôbre o ensino superior, atribuição exclusiva, aliás, que continuou até hoje, na República.

Por lei de 11 de agosto de 1827 são creados os Cursos Jurídico-Sociais de Olinda, ao Norte, e de São Paulo, ao Sul. O de Olinda passa a funcionar, no Recife, em 1854, quando as duas Academias Jurídicas transformam-se em Faculdades de Direito federaes.

Importantíssima a influência exercida, através dos anos, pelos dois prestigiosos e acatados institutos de ensino superior.

"A criação de faculdades brasileiras - escreveu Sylvio Romero - foi de um alcance intelectual extraordinário; logo na esfera política e administrativa, começamos a ter homens como Euzebio, Zacarias, Nabuco, Rio Branco e oitenta outros que são filhos de academias nacionais e alguns dêles não puzeram jamais os pés na Europa, ou os puzeram ràpidamente. Foram sempre os melhores". 
A referência do eminente crítico se dirige mais, como se vê, aos nomes que desfrutaram de prestígio na alta política e na administração do país. A êsses, entre os oitenta aludidos e outros mais, poder-se-á acrescentar os nomes de José de Alencar, Gaspar Silveira Martins, Rui Barbosa, Joaquim Nabuco, Barão do Rio Branco, José Bonifácio (o moço), Sinimbú, Cotegipe, Saldanha Marinho, João Alfredo, Dantas, Francisco Otaviano, Ferreira Viana, Visconde de Ouro Preto, Americo Lobo, Campos Sales, Prudente de Moraes, Rangel Pestana; Afonso Pena, Brazilio Machado e tantos outros.

Quanto aos juristas, pròpriamente, cultores da ciência do direito, escritores, jurisconsultos, há a destacar, entre dezenas de nomes de maior relêvo, os de Teixeira de Freitas, que se matriculou em Olinda em 1832, se transferiu para São Paulo, onde fez o segundo, o terceiro e o quarto anos, e foi formar-se em Olinda em 1837; Carvalho Moreira, João Mendes de Almeida, Sylvio Romero, Candido Mendes de Almeida, Paula Batista, Pimenta Bueno, Barão de Ramalho, Perdigão Malheiro, Felicio dos Santos, José Antonio Saraiva, Rui Barbosa, Lafayette Rodrigues Pereira, João Mendes de Almeida Junior, Tavares Bastos, João Monteiro, Tobias Barreto, Clovis Bevilaqua, Carlos de Carvalho, Barros Pimentel, João Monteiro, Almeida Nogueira, Pedro Lessa, Epitacio Pessoa e J. C. Carvalho de Mendonça.

São de mencionar ainda os nomes de mais repercussão nas letras nacionais, de Castro Alves, Alvares de Azevedo, Maciel Monteiro, Fagundes Varela e Tobias Barreto, focos de irradiação da fase da literatura romântica dentro das academias, talentos postos também a serviço das novas idéias que culminaram com a abolição da escravatura, a proclamação da república, a federação.

Escreveu o professor Haroldo Valladão: "Olinda e São Paulo pela Academia e pelo Curso Anexo, com aqueles estudos de filosofia e letras e de ciências jurídicas e sociais, políticas e econômicas, nas aulas menores, de preparatórios, e maiores, do "curriculum", com os exames e os atos, as defesas de teses e 
os concursos, as congregações, festas e solenidades escolares formaram uma população intelectualmente ativa, ávida de ciência e de erudição, em contínua efervescência espiritual, que se expande através da imprensa acadêmica..... "A juventude brasileira que se desejava preparar para os postos de govêrno, para os cargos da administração, da política, da magistratura, que desejava se aprimorar no estudo das ciências e letras, no jornalismo, na crítica, nos debates públicos, corria para um daqueles núcleos do Norte e do Sul”.

3. - A referência nominal (muito incompleta) aos vultos brasileiros oriundos das duas escolas de Direito, de Olinda (depois Recife) e São Paulo, se restringe àqueles de mais evidência até os começos do século atual. Porque, na República, em janeiro de 1891, o Govêrno Provisório institui o regime das Faculdades Livres, permitindo sua creação por iniciativa privada. Fundam-se então no Rio de Janeiro a Faculdade de Ciências Jurídicas e Sociais e a Faculdade Livre de Direito, em 1892; a Faculdade de Direito do Estado de Minas Gerais em 1893; Faculdades de Direito de Porto Alegre, do Ceará e do Pará, tôdas reconhecidas pelo Govêrno Federal, que junto delas mantém um inspetor, sendo que o reconhecimento das três últimas data de 1903. Esse número triplicou neste meio século decorrido.

Era habitual , nos primeiros decênios de existência das duas Faculdades oficiais, transferirem-se os estudantes de uma para outra, consoante aconteceu com Teixeira de Freitas, primeiramente, e depois com Rui Barbosa, Barão do Rio Branco, Joaquim Nabuco, José de Alencar, Fagundes Varela, Castro Alves e outros. De apreciável utilidade era êsse intercâmbio, que facilitava maior contacto e melhor conhecimento entre elementos representativos da inteligência do Norte e do Sul, fortalecendo a unidade brasileira.

Formava-se assim a nossa cultura jurídica, emancipada da de Portugal. E os frutos foram aparecendo através de leis bem redigidas e bem lançadas e de obras nacionais de notável valor. 
A evolução do Brasil, na sua estrutura política e jurídica, se opera com a influência do bacharel, do doutor em leis. Era a carreira que atraía sempre o maior número de candidatos, si não tanto pelo exercício profissional que o diploma autorizava, pela soma de conhecimentos gerais nas ciências jurídicas e sociais que o curso proporcionava e ainda pelo prestígio que dava aos graduados, integrando-os na elite intelectual dominante. $O$ grau facilitava o acesso aos cargos públicos, o desempenho de funções da alta administração e da política.

Em geral com a visão mais esclarecida, maleabilidade intelectual na compreensão dos fatos e das coisas, maiores recursos de expressão verbal, certa propensão para as belas letras, e avultando ainda mais em número do que os diplomados por outros cursos, os homens do direito predominavam na direção dos negócios públicos, nos gabinetes ministeriais, no parlamento, durante o Império, e continuaram com essa ascendência na República.

Os moços tem sido sempre atraídos, e isso até hoje, quando o ensino profissional está difundido através de tantos estabelecimentos de ensino superior, para os cursos de direito, medicina e engenharia, na conquista do gráu que os coloque em posição destacada na sociedade, embora, na maioria dos casos, não se dediquem à atividade profissional que o diploma lhes faculta, mas a outros misteres.

Observa com acêrto o escritor Fernando de Azevedo, na sua erudita obra "A Cultura Brasileira": - "Nenhuma instituição de ensino superior estava mais predestinada do que as escolas de direito a exercer essa função supletiva, não só pelo caráter mais filosófico de seus estudos e pela maior aplicação das letras às atividades de carreira, como porque, de tôdas as faculdades de preparação profissional, são as de direito, pela própria natureza de seus cursos, que põem a sua razão de ser, de preferência, no elemento cultural, e não no elemento económico e técnico, e desenvolvem uma fé mais robusta no poder espiritual, na virtude unificadora da inteligência e dos valores morais. As faculdades de direito foram, pois, o viveiro de uma 
elite de cultura e urbanidade, em que recrutaram numerosos elementos a administração e a política, o jornalismo, as letras e o magistério (e até mesmo o teatro), infiltrados de bachareis, desertores dos quadros profissionais de que guardaram, com a ilustração, apenas o título e o anel de rubi no dedo, como sinais de classe e de prestígio". (pag. 156). E adiante: "Enquanto ao norte do continente americano se realizava, sob o impulso de suas imensas riquezas minerais e da exploração industrial do subsolo, um desenvolvimento "unilateral quase exclusivamente baseado no progresso das coisas materiais", desabrochava no Brasil, como uma flor de civilização, a cultura jurídica, poderosamente alimentada nas tradições morais e religiosas da nação. Durante mais de um século ou por quase todo o período que se seguiu à Independência Nacional, foi a voz do direito que se ergueu mais alto, e nas academias e à sombra delas é que a vida intelectual adquiriu maior intensidade e mais poder de projeção". (pag. 167).

4. - Traçado assim sucintamente o panorama nacional das atividades desenvolvidas no domínio do estudo do direito, é chegada a ocasião de enquadrar a última Província, mais tarde Estado do Paraná, no âmbito da influência dessa manifestação de vitalidade, para saber quanto dela se beneficiou essa nova unidade política.

Os núcleos primitivos de povoação do território paranaense foram os arraiais de Paranaguá e de Curitiba, elevados à categoria de vilas respectivamente em 1648 e 1693. Paranaguá logrou maior desenvolvimento nos séculos XVII e XVIII. Foi capitania de 1660 a 1710, passando depois a pertencer à capitania de São Paulo, formada das antigas donatarias de São Vicente e Santo Amaro e que abrangia, entre outras, as vilas de Paranaguá e Curitiba. No plano judiciário da capitania, Paranaguá se tornou em 1725 ouvidoria, separada da de São Paulo. Compreendia então a Ouvidoria de Paranaguá todo o sul do Brasil, até o Rio da Prata e lhe pertenciam, além de Curitiba, as vilas marítimas de Iguape, Cananéa, São Francisco, Desterro e Laguna. Com o correr do tempo, a ouvidoria foi desdobrando-se em outras que dela se separavam. Finalmente, por alvará 
régio de 19 de março de 1812 , a sede da comarca, com a residência dos ouvidores, foi deslocada para Curitiba, ficando $\mathrm{Pa}-$ ranaguá com um lugar de Juiz de Fora do Civel, Crime e Orfãos, isso (diz o alvará) "atendendo à mais fácil administração da justiça e ser mais própria para a residência dos Ouvidores a Vila de Curitiba, por ser mais central e bastantemente populosa".

Nasceu o povoamento destas paragens sob o influxo da atração que provocava nos ádvenas de outras plagas as aluviões auríferas, objeto de exploração, de inspeção oficial e da instalação da Casa de Fundição para barretagem, marcação e separação dos quintos de ouro destinados ao rei de Portugal.

Sobrevêm os acontecimentos políticos, sociais, administrativos, culturais no período da permanência de D. João VI e sua côrte no Rio de Janeiro, seu regresso a Portugal, proclamação da Independência do Brasil, creação das províncias pela carta constitucional de 1824, abdicação de D. Pedro I, Regência, Maioridade de D. Pedro II. À 5 de fevereiro de 1842, o Presidente da Província de São Paulo sanciona a Lei $n .^{\circ} 5$ decretada pela Assembléia Legislativa Provincial, pela qual ficaram elevadas à categoria de cidades as vilas de Curitiba, Paranaguá, Itú, Sorocaba, Taubaté e Campinas.

5. - Curitiba constituia a extensa comarca da Província de São Paulo e abrangia todo o imenso território que veiu depois a formar a Província do Paraná. Ao ser elevada a Província, em 1853, por lei imperial, a dita Comarca se compunha dos seguintes Têrmos Judiciários:

a) - de Curitiba, compreendendo a sua sede, a Vila Nova do Príncipe (Lapa), a vila de Guarapuava, as freguesias de São José dos Pinhais e de Campo Largo, da Palmeira, do Rio Negro e vários povoados como o de Campina Grande, do Arraial Queimado, do Pacotuba, de Votuverava, da Ribeira et.; b) - de Paranaguá, compreendendo a sede, a vila de Morretes, a de Antonina, a freguesia de Guaraquessaba, de Superaguí, do Anháia etc.; c) - de Castro, compreendendo a sede, as freguesias de Jaguariaíva, do Tibagí e de Ponta Grossa; e os povoa- 
dos de Catanduvas, Furnas, Piraí, São João do Cristianismo, dos Carrapatos, de Itaiacóca, Conchas, Cupim, etc.

Instalada a Província e escolhida Curitiba para sua Capital, contava o território do Paraná duas cidades, Curitiba, com 5.819 habitantes, Paranaguá com 6.533; sete vilas: Antonina, com 4.160; Morretes, com 3.709; Guaratuba, com 1.563; São José dos Pinhais, com 4.600; Lapa, com 5.406; Castro, com .. 5.899, e Guarapuava, com 2.600; seis freguesias: Campo Largo, com 3.690 habitantes; Palmeira com 1.818; Ponta Grossa, com 3.033; Jaguariaíva, com 1.071; Tibagí, com 1.040 e Rio Negro, com 1.884, e ainda quatro capelas curadas: Guarakessaba, com 3.876; Iguaçu (hoje Araucaria), com 1.562; Votuverava, com 2.018 e Palmas, com 734 .

A população total da nova Província era, pois, em 1853, de 62.258 habitantes, sendo 31.219 homens e 31.039 mulheres, na grande maioria brancos, seguindo-se, na mescla racial, mulatos, mamelucos e cafusos, e, por último, os pretos, inclusive alguns milhares de escravos. Os índios ainda não integrados no amálgama dos cruzamentos viviam no sertão lingínquo, em tribus que foram sendo aos poucos catequizadas, e das quais existem hoje apenas algumas centenas de indivíduos remanescentes.

Curitiba tinha então apenas duas escolas primárias oficiais, uma para o sexo masculino e outra para o sexo feminino. Paranaguá, sob o ponto de vista urbano, social e comercial, era mais importante do que a Capital. Possuia Paranaguá dezenas de sobrados, quasi todos construidos no século XVIII, bem como o edifício do Colégio dos Jesuitas, que data de 1.740 .

6. - São de imaginar, por essas eras, o primitivismo das construções de casas, na maioria; do vestuário, com o habitual pala, e os costumes, em que se sobressaem o uso do cavalo e do mosquete. As distâncias eram transpostas através dos rios ou de caminhos para tropas, com demorado percurso, que durava sete dias de Paranaguá a Curitiba, até que a estrada da Graciosa, acabada de construir sòmente em 1873, trouxe maior facilidade de comunicação entre o litoral e o planalto. 
Data de 1829 o comêço da imigração para o Paraná, cujo maior problema passou a ser, desde então, como ainda hoje, o da colonização, ante a necessidade, sempre presente, de gente para povoar, trabalhar e produzir. Levas, encaminhadas pelos poderes públicos, de imigrantes alemães, italianos e poloneses, principalmente, foram formando colonias e adensando os núcleos de população já existentes. Outros adventícios, sirios, espanhóis, portugueses, judeus, foram contribuindo para o povoamento e o progresso, a par do elemento nacional já estabilizado e em atividade produtiva.

As enormes fazendas de criação, formando o clan de agregação dos habitantes circunvisinhos e dos escravos em tôrno do chefe dos latifúndios, equiparado a um senhor feudal, dos tempos coloniais, foram cedendo o passo a outras formas de subordinação ou cooperação. Intensificou-se a cultura da terra, aumentaram os rebanhos da criação. A vida rural foi tomando maior desenvolvimento.

7. - Com o crescimento da população, os recenseamentos gerais do país acusaram cifras de aumento porcentual de habitantes no Paraná maiores do que nos outros Estados, passando em 1900 a 331.509 habitantes, inclusive 50.124 em Curitiba. Conta atualmente o Estado 2.400 .000 habitantes e Curitiba cerca de 200.000 .

Na lenta evolução em que Paranaguá se conservou vila durante perto de duzentos anos e Curitiba durante cerca de cento e cinquenta anos, e outros núcleos de população pouco desenvolvimento experimentaram, até o começo dêste século, não é difícil imaginar como se portavam os paranaenses a respeito da cultura do espírito e si lhes interessava a aquisição de diplomas de bacharelado e doutcramento. A aristocracia rural, em que a extração e exportação da herva-mate já tornavam incremento, ao lado do pastoreio, parecia interessar-se mais pelos títulos nobiliários.

$\mathrm{Na}$ história das sociedades, das instituições, dos empreendimentos que tomam vulto, os nomes dos pioneiros são sempre assinalados. Fatos de muito maior monta e feitos mais valoro- 
sos poderão sobrevir, mas já desaparecem na intensividade das realizações com a cooperação de muitos, anulando-se quase o merecimento do esfôrço individual.

E' de notar a carência de homens de cultivo intelectual no Paraná quando se organizou a Província. Romario Martins anota: "Curitiba era, na época de sua elevação a Capital, uma insignificância que de cidade só tinha o predicamento oficial. Para instalar a Província, o conselheiro Zacarias de Góes e Vasconcelos, seu primeiro Presidente, não podia contar, como não contou, com nenhum espírito de resolução e de iniciativa. Todos os elementos locais juntos não valiam um homem como êle. Escolheu, dentre os mais prestigiosos e de certo lustre na sociedade local, os que eram precisos para a composição da Assembléia Legislativa Provincial”.

Dentre os deputados escolhidos figura o jovem Jesuino Marcondes de Oliveira e Sá, nascido na Palmeira em 1827 e formado pela Faculdade de Direito de Olinda em 1849. Foi deputado à Assembléia Provincial em três biênios, deputado à Câmara dos Deputados do Império em três legislaturas, Ministro da Agricultura, nomeado em 1864, e Presidente da Província do Paraná ao ser proclamada a República. Aliás, entre tantos nomes ilustres que exerceram o cargo de Presidente da Província do Paraná, como o coselheiro Zacarias, o dr. Sancho de Barros Pimentel, o dr. Carlos de Carvalho, o dr. Brazilio Machado de Oliveira, o dr. Alfredo d'Escragnolle Taunay, verifica-se, na relação respetiva, que o conselheiro Jesuino Marcondes, como vice-presidente, ocupara já a presidência da Província nos anos de 1878, 1879 e 1882.

Especial relêvo merece igualmente o nome do dr. João da Silva Carrão, nascido em Curitiba, em 1810, formado pela Faculdade de Direito de. São Paulo, da qual foi professor catedrático de 1845 a 1879. Teve assento na Assembléia Provincial de São Paulo em sete biênios e, durante oito legislaturas, na Assembléia Geral do Império. Foi ainda senador por São Paulo, Presidente das Províncias de São Paulo e do Pará, tendo também ocupado a pasta da Fazenda no Gabinete do Marquês de Olinda. Faleceu em 1888. 
8. - Merecem ainda ser focalizados os nomes de bachareis em direito nascidos no vasto território da comarca paulista de Curitiba, antes de sua emancipação política para ser erigida à categoria de Província, nomes êsses de personalidades de relêvo na órbita nacional, reconhecidamente paranaenses pela origem e pelas ligações de suas atividades com o rincão de seu nascimento. E ante a deficiência de população e na estreiteza do meio cultural da época, não poderiam ser muitos os que se destacaram pelo mérito de seus título de homens de lei.

São de notar os drs. José Joaquim Pedrosa, Agostinho Ermelino de Leão, Brasílio Itiberê da Cunha, Ildefonso Xavier Ferreira (padre), Manoel Francisco Correia, Manoel Alves de Araujo, Generoso Marques dos Santos e Ubaldino do Amaral.

Nascidos também antes da instalação da Província, no seu território, mas com atividade desenvolvida mais na esfera provincial, merecem menção os nomes dos drs. Joaquim de Almeida Faria Sobrinho, Emygdio Westphalen, Joaquim Ignacio Silveira da Mota; Francisco Xavier da Silva, Joaquim Antonio de Oliveira Portes, Francisco Alves Guimarães, Euzebio Silveira da Mota, José Pereira dos Santos Andrade, grupo a que não fica mal adicionar o nome ilustre no âmbito nacional, do dr. Vicente Machado da Silva Lima, nascido em Castro em 1860, todos diplomados pela Faculdade de Direito de São Paulo, a exceção do dr. Santos Andrade, que se formou pela do Recife.

Essa visão retrospectiva abrange os homens graduados em direito do passado mais remoto e que, graças aos seus títulos acadêmicos, seus conhecimentos, sua experiência, desempenharam funções públicas relevantes no século dezenove, chegando alguns a exercê-las até os dois primeiros decênios do presente século.

9. - Continuaram, os paranaenses que dispunham de recursos para ir estudar fora, a procurar os cursos de ensino superior de São Paulo e Rio de Janeiro, de preferência, notadamente os de direito, medicina e engenharia. 
Com apoio na lei orgânica de 1911, desoficilizando o ensino e permitindo a criação de faculdades particulares, fundou-se, por iniciativa de um grupo decidido de homens de ideal e de ação prática, a 19 de dezembro de 1912, a Universidade do Paraná.

Sobrevindo a nova lei orgânica de 1915, que oficializou novamente o ensino e criou condições relativas ao número de habitantes das cidades e certo patrimônio próprio para a existência de escolas superiores, os cursos componentes da Universidade se desmembraram e esta legalmente desapareceu.

Passaram então a funcionar separadamente, embora sob a mesma cúpola do edifício da Universidade, as Faculdades de Direito, Engenharia e Medicina. Sòmente em 1946 se conseguiu a reestruturação da Universidade do Paraná, que passou afinal, em 1950, a constituir, sob êsse nome, um estabelecimento federal, no plano do ensino superior do país, ao lado de congêneres de outras capitais.

A Faculdade de Direito do Paraná, ora incorporada na Universidade, foi reconhecida oficialmente por portaria ministerial de 19 de agosto de 1920. E desde 1917 dela vêm saindo turmas de bachareis, mais numerosas ultimamente, com o progresso do Estado, aumento de sua população e procura da Faculdade por estudantes de outros Estados.

As gerações paranaenses de candidatos a pergaminho, nestas últimas quatro décadas, encontraram mais possibilidade de levar a efeito a conquista de um diploma profissional de curso superior tendo escola mais à mão.

10. - Mas, o Paraná recebeu, na sua formação jurídica, para organização e funcionamento de suas instituições públicas, de seus serviços de justiça, a cooperação eficiente e valiosa de inúmeros bachareis em direito provindos de outros Estados do Brasil, mais dos do Norte, principalmente do Nordeste, formados a maioria na Faculdade de Direito do Recife.

Os "bachareis do norte", como eram chamados, na deficiência de campo onde exercer sua atividade especializada nos 
Estados a que pertenciam, demandavam frequentemente o Sul do país, região de sempre crescente prosperidade, com ampliação de novas circunscrições judiciárias que requeriam o aproveitamento do bacharel nas funções de juiz, promotor, delegado de polícia, e atraíam os advogados para postularem em juizo.

Em geral dotados de boa cultura jurídica, dom oratório, muita sociabilidade, índole familiar, acentuado espírito de brasilidade, constituiam-se em elementos de valiosa colaboração nas comarcas incipientes para formação e desenvolvimento do núcleo social. E na carreira iam até os altos postos da judicatura, compondo sempre, até há poucos anos, a maioria do Tribunal de Justiça. E têm exercido também o magistério superior, com a creação da Universidade, desde seu início em 1912.

11. - No ano próximo passado fundou-se em Curitiba mais um curso jurídico, a Faculdade de Direito de Curitiba, que, funcionando, já no segundo ano, sob o regime de inspeção federal, se prepara para obter sua equiparação aos congêneres. Igualmente, desde 1952 está funcionando nesta cidade um Curso de Legislação Sindical do Trabalho. E filiada à Universidade há a Faculdade de Ciências Económicas, na qual são também lecionadas disciplinas jurídicas.

12. - Os trabalhos jurídicos de paranaenses ou produzidos no Paraná têm sido divulgados em geral mediante livros, estudos nas revistas especializadas, anais de conferências, congressos jurídicos e parlamentos, teses para defesa em concursos, pareceres, folhetos, além das publicações frequentes de arrazoados forenses focalizando causas defendidas na esfera judiciária. 